\title{
Wind Turbine Performance in Controlled Conditions: BEM Modeling and Comparison with Experimental Results
}

\author{
David A. Johnson, Mingyao Gu, and Brian Gaunt \\ Department of Mechanical and Mechatronics Engineering, University of Waterloo, Waterloo, Canada N2L 3G1 \\ Correspondence should be addressed to David A. Johnson; da3johns@uwaterloo.ca
}

Received 17 December 2015; Accepted 24 April 2016

Academic Editor: Funazaki Ken-ichi

Copyright ( 2016 David A. Johnson et al. This is an open access article distributed under the Creative Commons Attribution License, which permits unrestricted use, distribution, and reproduction in any medium, provided the original work is properly cited.

Predictions of the performance of operating wind turbines are challenging for many reasons including the unsteadiness of the wind and uncertainties in blade aerodynamic behaviour. In the current study an extended blade element momentum (BEM) program was developed to compute the rotor power of an existing $4.3 \mathrm{~m}$ diameter turbine and compare predictions with reported controlled experimental measurements. Beginning with basic blade geometry and the iterative computation of aerodynamic properties, the method integrated the BEM analysis into the program workflow ensuring that the power production by a blade element agreed with its lift and drag data at the same Reynolds number. The parametric study using the extended BEM algorithm revealed the close association of the power curve behaviour with the aerodynamic characteristics of the blade elements, the discretization of the aerodynamic span, and the dependence on Reynolds number when the blades were stalled. Transition prediction also affected overall performance, albeit to a lesser degree. Finally, to capture blade finite area effects, the tip loss model was adjusted depending on stall conditions. The experimental power curve for the HAWT of the current study was closely matched by the extended BEM simulation.

\section{Introduction}

With wind energy becoming an important part of the energy mix for many countries it is desirable to improve our understanding of its potential power output. Ideally the loading on a wind turbine at a specific wind speed and its corresponding power production would be known prior to construction and installation. Knowledge of a turbine's power output and loading not only helps with the design of turbine components such as nacelle bearings or tower structure but also bears financial implications when assessing the feasibility of wind as alternative energy.

The power output of a wind turbine is closely associated with the blade aerodynamics. One commonly used approach to predict the power produced by a rotor, given the blade airfoil aerodynamic properties, is the blade element momentum (BEM) theory. In the current study a MATLAB ${ }^{\circledR}$ program, herein referred to as "extended BEM," was developed to compute the rotor power of a turbine. Beginning with blade geometry, it integrated the BEM analysis into the program workflow. To examine its accuracy the model predictions of the blade performance were compared to the experimental power measurements collected on a custom-built, threebladed, horizontal-axis wind turbine (HAWT) $[1,2]$. The testing was completed at a wind generation facility capable of producing controlled wind speeds at the University of Waterloo. Due to the custom turbine and wind facility it was possible to test the turbine performance over a wide range of wind speeds and rotational rates, which formed a unique aspect of this study.

While other data sets are available for testing wind turbine performance models $[3,4]$, it has been shown that model predictions still vary widely. Therefore, the data on the experimental turbine used in this study and its test conditions will be provided in hopes of allowing other researchers to verify their respective models.

The paper is organized as follows. The wind facility and turbine parameters will be briefly outlined, followed by a detailed description of the extended BEM workflow and its input parameters. A comparison of the model predictions 
with the collected experimental data will then be presented and discussed.

\section{Experimental Equipment}

2.1. Wind Facility. The wind generation facility where all experiments were conducted was an open-looped tunnel with 6 identical fans located near its entrance. The fans were arranged in a 2 by 3 array and drove the flow at adjustable flow rates. Each fan generated a maximum air flow of $78.7 \mathrm{~m}^{3} / \mathrm{s}$ at $413.5 \mathrm{~Pa}$. The air flow was discharged into a $8.54 \mathrm{~m}$ long by $8.23 \mathrm{~m}$ wide by $5.9 \mathrm{~m}$ high plenum, where it was conditioned before entering a $19.5 \mathrm{~m}$ long and $15.4 \mathrm{~m}$ wide test area that was $7.8 \mathrm{~m}$ high at the sides and $13 \mathrm{~m}$ high at the peak of a pitched roof. With the turbine installed in the test area, the maximum nominal wind speed attained during testing was $11.1 \mathrm{~m} / \mathrm{s}$. Further details regarding the geometry and flow analysis of this facility can be found in $[1,2,6]$.

2.2. Turbine. The HAWT used for the current study had a $4.3 \mathrm{~m}$ diameter rotor. The hub was located $3.1 \mathrm{~m}$ above the ground. The shaft tilt and nacelle yaw angles were set to zero. The blades were made from an existing blade mould and design and assembled without upwind or downwind preconing. During experimentation the turbine rotor plane was located $7.96 \mathrm{~m}$ downstream of the test area inlet in the flow direction. Power production tests were conducted for a nominal wind speed range of $6.4 \mathrm{~m} / \mathrm{s}$ to $11.1 \mathrm{~m} / \mathrm{s}$ while the turbine shaft rotational rate varied from $40 \mathrm{rpm}$ to $200 \mathrm{rpm}$. More details of the turbine in relation to testing can be found in work by Gaunt and Johnson [1].

2.3. Blades. In order to effectively model the performance of the wind turbine, the geometry of the manufactured blades was determined, including the chord, twist, and airfoil distributions.

The aerodynamic span of the blade did not start until a radius ratio of approximately $23 \%$, where the cross-sectional profile transitioned from a chamfered rectangle to an airfoil. From the root to the tip of the aerodynamic span the blade chord, $c$, decreased linearly from $0.18 \mathrm{~m}$ to $0.046 \mathrm{~m}$ :

$$
c=-0.174 \times\left(\frac{r}{r_{T}}\right)+0.220(\mathrm{~m})
$$

with $r$ representing the radial position measured with respect to the centre of rotation and $r_{T}$ the tip radius.

The twist of the blade, $\beta$, is herein defined as the angle between the local chord of a section of the blade and the tip chord. Accordingly, the tip twist angle is $0^{\circ}$ by definition. Moreover, the tip pitch angle, $\theta_{T}$, is herein defined as the fixed angle between the tip chord and the plane of rotation. Therefore, the local pitch of the blade, $\theta$, that is, the angle between the local chord and the rotor plane (Figure 1), is the sum of $\beta$ and $\theta_{T}$. As per the foregoing definitions the tip pitch angle of the HAWT blade used for the current study was found to be $3^{\circ}$. The twist angle distribution, instead of monotonically decreasing toward the tip, was found to be irregular. Consequently, a look-up table was prepared, given in Table 1 ,
TABLE 1: Twist angle distribution of the manufactured turbine blades.

\begin{tabular}{lc}
\hline $\begin{array}{l}\text { Radius ratio } \\
r / r_{T}\end{array}$ & $\begin{array}{c}\text { Twist angle } \\
\beta(\mathrm{deg})\end{array}$ \\
\hline 0.25 & 8.25 \\
0.31 & 5.88 \\
0.41 & 3.85 \\
0.51 & 2.09 \\
0.61 & 2.16 \\
0.71 & 3.32 \\
0.80 & 1.55 \\
0.90 & 0.56 \\
1.00 & 0.00 \\
\hline
\end{tabular}

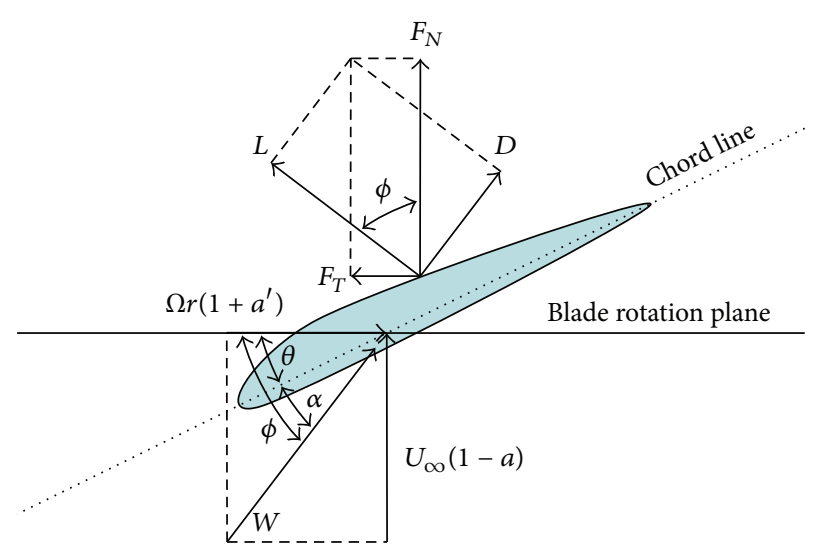

FIGURE 1: Velocity and force triangles for an airfoil section of a rotating wind turbine blade.

which listed the blade twist angle at regular radial positions along the blade.

The airfoil distribution was determined at three points along the blade: root, midsection, and tip of the aerodynamic span, that is, $23 \%, 61.5 \%$, and $100 \%$ of $r_{T}$. The measured profiles for each blade section from root to tip, smoothed by the AFSMO program [7] and scaled with respect to the local chord length, are shown in Figure 2. Smoothing of the profiles was critical for the XFOIL subroutines to converge (see Section 3.2). The measured tip profile is plotted against NACA 4415 airfoil [8] to show the close approximation of the former to the latter, which will be elaborated on in the subsequent sections. The maximum thickness and camber and their locations on the unit-length chord of the respective airfoils at the aforementioned three points along the blade are summarized in Table 2.

\section{Methodology}

The mathematical procedure for predicting the power performance used in the current study was based on the classical BEM theory but extended it such that the input data to the BEM algorithm was computed from the blade geometry and included in the iterative procedure of BEM. 


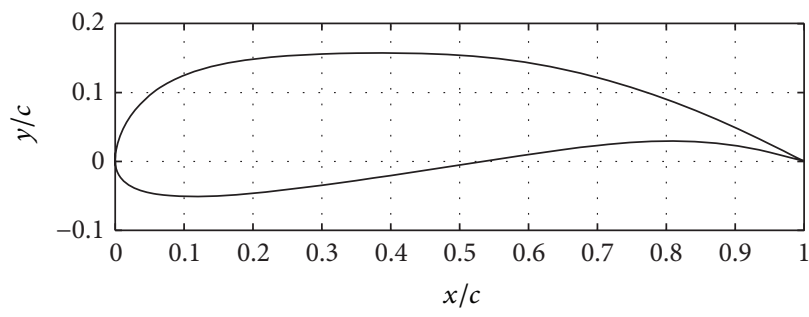

(a)

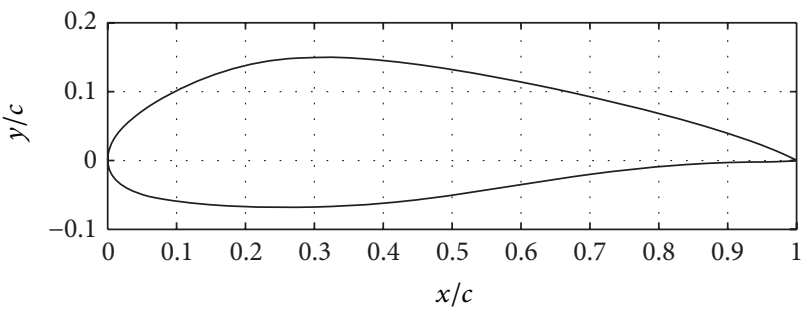

(b)

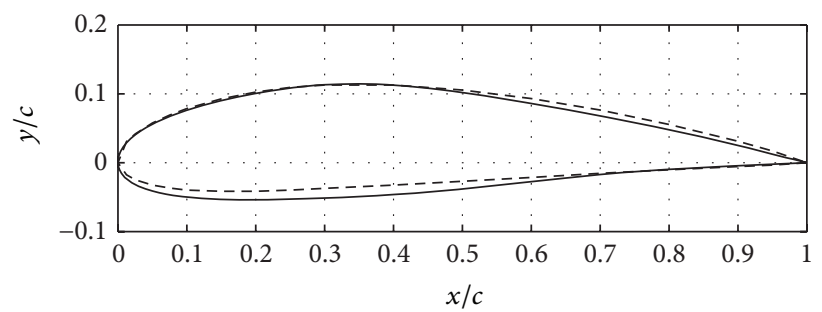

(c)

FIGURE 2: Measured blade airfoil coordinates: (a) root; (b) midsection; (c) tip with NACA 4415 airfoil (dashed line).

TABle 2: Maximum thickness and camber and their respective locations on the unit-length chord of each blade section at three radial positions: root, midsection, and tip of the aerodynamic span.

\begin{tabular}{lccc}
\hline & Root & Midsection & Tip \\
\hline Maximum thickness & 0.195 & 0.217 & 0.164 \\
at $x$ & 0.225 & 0.300 & 0.325 \\
\hline Maximum camber & 0.0755 & 0.0406 & 0.0326 \\
at $x$ & 0.600 & 0.375 & 0.400 \\
\hline
\end{tabular}

3.1. Classical BEM Theory. BEM estimates the aerodynamic forces on a turbine blade and from there estimates overall turbine loading and power production. It can be employed for many design and analysis purposes such as an estimation of the forces that blades could exert on a support structure. Details of the general method can be found in [9-11].

3.1.1. Assumptions. A basic BEM implementation relies on several assumptions to simplify the problem to a suitable level for initial turbine analysis [9]. The first assumption is that there is no flow along the blade in the spanwise direction. Adjacent elements therefore have no effect on each other, implying that the force on each element is based on the lift and drag of a 2D airfoil given identical relative velocity and angle of attack. While radial flow occurs particularly near the tip, the assumption was necessary in order to simplify the model. Prandtl's tip loss model can be employed to compensate for the error stemming from this simplification.

Moreover, it is assumed that the incoming wind speed does not vary based on the position of a blade in the rotation, which effectively states that there is no yawed flow or wind shear present. Based on the wind facility design investigated in a previous study [1], the wind shear assumption was considered valid due to the wind speed control. The yawed flow condition was satisfied by orienting the rotor plane to be perpendicular to the upwind flow, thereby producing zero yaw.

3.1.2. Procedure Overview. The BEM algorithm begins by dividing the blade into a user-specified number of elements. For every blade element the relative wind speed, $W$, and the angle of attack, $\alpha$, are then determined by way of an iterative procedure that incorporates local aerodynamic events into momentum conservation over a control volume formed around the blade element. The parameters that indicate convergence of iterations are known as the axial and tangential induction factors (Figure 1). The axial induction factor, $a$, represents effectively the reduction in the incoming wind speed, $U_{\infty}$, due to the momentum exchange between the wind and the turbine. The tangential induction factor, $a^{\prime}$, is introduced to capture the increase in the tangential velocity, $\Omega \times r$, due to the wake rotation. For simplicity the initial values for $a$ and $a^{\prime}$ are often set to zero.

Once the iterative procedure converges, the coefficients of lift and drag, $C_{L}$ and $C_{D}$, can be determined from $W$ and $\alpha$, and subsequently the lift and drag forces, $L$ and $D$, can be computed. In order to determine the power produced by the rotor, it is assumed that $L$ and $D$, obtained at the midpoint between element stations, act across the whole width of the element, which becomes increasingly valid as the number of blade elements is increased. Moreover, the nonaerodynamic part of the blade does not contribute to rotor power production. $L$ and $D$ are in turn transformed into a second pair of orthogonal force components: one tangential to the rotor plane, $F_{T}$, which contributes singularly to torque, and the other normal to the rotor plane, $F_{N}$, which contributes singularly to thrust. The force relations are shown in Figure 1. Summation of $F_{T} \times r$ from every blade element yields the shaft torque, from which the power produced by one blade is determined according to Euler's turbine equation with its implicit assumptions [10] and is multiplied by the number 


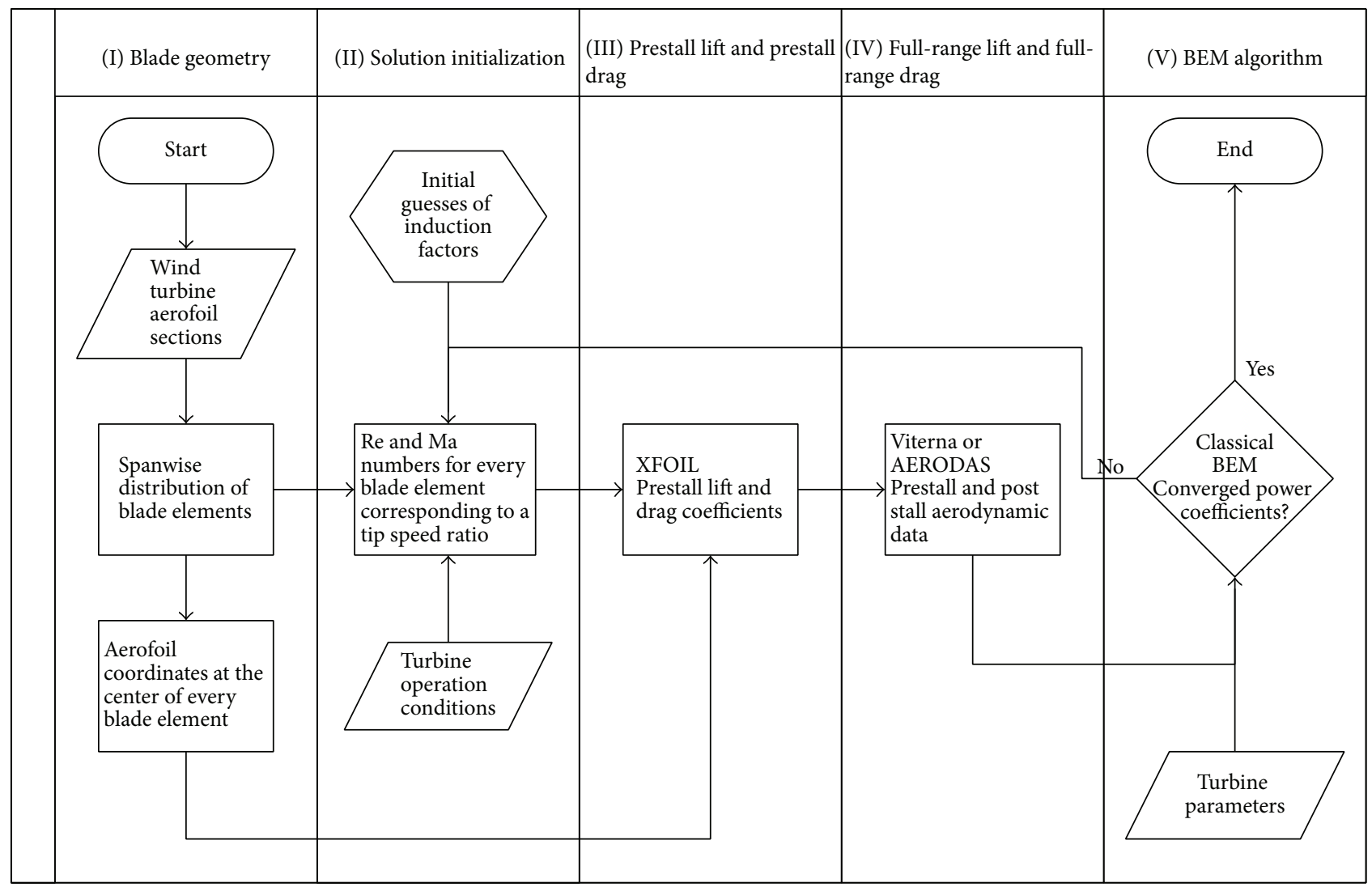

FIGURE 3: Flowchart of the extended BEM procedure for calculating wind turbine performance.

of blades to give the total power produced by the rotor. The total power scaled by the available power gives the power coefficient, $C_{p}$.

3.2. Extended BEM Procedure. According to the classical BEM theory the aerodynamic forces on the blades depend solely on the lift and drag characteristics of the airfoil shape of the blade elements, which poses challenges for implementation from several perspectives. First of all, a modern turbine blade is often obtained by solid fitting through a series of wellestablished aerodynamic profiles, leading to blended cross sections whose coefficients of lift and drag, $C_{L}$ and $C_{D}$, are not readily available. Consequently, for ease of implementation the 2D aerodynamic properties of well-established airfoil shapes that have been obtained experimentally at select Re are often used to represent the entire blade throughout the iterative procedure. In addition, $C_{L}$ and $C_{D}$ are functions of Reynolds and Mach numbers, Re and Ma. The dependence on $\mathrm{Re}$ is, in particular, prominent in the range between $1.0 \times 10^{4}$ and $1.0 \times 10^{6}[12]$, to which range the HAWT used for the current study belonged. Re and Ma in turn depend on the turbine blade relative wind speed, $W$. Moreover, $W$ is a function of axial and tangential induction factors, $a$ and $a^{\prime}$, which are computed iteratively until a desired tolerance is reached. As a result, $C_{L}$ and $C_{D}$ input to the BEM algorithm should be modified with every iteration in accordance with the changes in induction factors.
The extended BEM algorithm addressed the aforementioned limitations by nesting the classical BEM theory in a more comprehensive performance calculation procedure, whose workflow is shown in Figure 3. Each step was implemented in the MATLAB language because it provided handling of large data structures, which arose from definition of the workflow components as separate class objects, and allowed for integration of external routines such as XFOIL described below. The MATLAB code was written so as to be applicable to any test case or blade design.

The extended BEM first introduced XFOIL [13] to calculate $C_{L}$ and $C_{D}$ up to just beyond maximum lift and drag based on the local airfoil profile and Re and Ma. XFOIL has proven suitable for the analysis of subcritical airfoils even with significant laminar separation bubbles [14]. A representative amplification factor for transition prediction, $N_{\text {crit }}$, was unknown due to the lack of experimental flow data in the vicinity of the blades, so $N_{\text {crit }}$ values ranging from 6 to 10 were examined. The input to XFOIL included the airfoil coordinates at the centre of every blade element, which were interpolated from the smoothed measured airfoil profiles at the root, midsection, and tip of the aerodynamic span, as well as $\mathrm{Re}$ and $\mathrm{Ma}$ for every blade element corresponding to a set of $a, a^{\prime}$, and tip speed ratio, $\lambda$, that is, $\Omega \times r_{T} / U_{\infty}$.

$\alpha$ range of a variable-speed, fixed-pitch wind turbine extends deep into stall. The prestall aerodynamic property data output by XFOIL would not be sufficient to provide 
the lift and drag values required by the BEM solver, so they were extrapolated to an angle of attack range from $-20^{\circ}$ to $90^{\circ}$ utilizing two separate poststall models, Viterna [15] and AERODAS [16]. Both poststall models not only served the purpose of extending the lift and drag coefficients into the poststall region with acceptable accuracy but also considered aspect ratio, AR, to account for the three-dimensional nature of flow over a turbine blade of finite length. Calculation of the prestall $C_{L}$ and prestall $C_{D}$ by XFOIL and extension into poststall by Viterna or AERODAS were both iterated to take into account the changes in $a$ and $a^{\prime}$ from one iteration to the next.

The full range of airfoil data served as input to a standard BEM calculation procedure (see Section 3.1.2) adjusted for Prandtl's tip losses with discretion, which was integrated as a concluding step in the iterative procedure. The procedure computed by iteration $a$ and iteration $a^{\prime}$ for every parametric combination based on a convergence criterion of $0.01 \%$ and from there output $C_{p}$, which was used to indicate "global" convergence of the extended BEM algorithm. If $C_{p}$ changed more than the desired tolerance, which was set to $0.1 \%$ in the current study, another iteration would be initiated, beginning with XFOIL recomputing the prestall aerodynamic property data with $a$ and $a^{\prime}$ obtained from the preceding iteration. The tip loss correction is worth further remark. Tangler and Kocurek [17] in their guidelines for applying the Viterna model to BEM analysis observed better power predictions when the finite AR effects were taken into account by simultaneously adjusting the $2 \mathrm{D}$ airfoil data for finite $\mathrm{AR}$ with the poststall model and enabling the tip loss model. However, it can be argued that using the tip loss model on airfoil data already adjusted for finite blade length would overly compensate for the effects of finite AR. As a result, in executing the extended BEM algorithm the tip loss model was turned off if the 2D airfoil data were corrected and turned on otherwise.

Following the above workflow a parametric study was carried out to investigate the impact of specific input parameters on modeling power performance. The four variables (shown in Table 3) used in the parametric study were the nominal wind velocity; the transition amplification factor; the poststall model; and the finite AR correction (either the poststall model or Prandtl's tip loss correction). In accordance with the wind facility testing, the incoming wind speed was fixed while the turbine shaft rotational speed was varied to produce the desired range of tip speed ratios. The maximum achievable $\lambda$ in experimental testing was 8 , where $C_{p}$ was a maximum. To allow the actual peak location to be identified, the range of tip speed ratios investigated with BEM modeling was increased to include $\lambda=10$.

3.2.1. Prestall Lift and Prestall Drag. In order to evaluate how XFOIL would perform in predicting prestall $C_{L}$ and prestall $C_{D}$ as a part of the extended BEM workflow, it was applied to NACA 4415 series airfoil section. NACA 4415 airfoil was chosen because it was closely approximated by the airfoil profile at the blade tip (Figure 2) and therefore characterized in part the aerodynamic behaviour of the turbine blade. While a number of experimental studies on NACA 4415 airfoil are available in the literature, for example, $[8,18]$, the wind tunnel data published by Ostowari and Naik [5] was
TABLE 3: Matrix of the parametric study carried out using the extended BEM algorithm.

\begin{tabular}{lc}
\hline$U_{\infty}$ & $7.3 \mathrm{~m} / \mathrm{s}, 11.1 \mathrm{~m} / \mathrm{s}$ \\
$N_{\text {crit }}$ & $6,7,8,9,10$ \\
Poststall model & Viterna, AERODAS \\
Finite AR correction & Poststall model, Prandtl's tip loss \\
\hline
\end{tabular}

selected for comparison with the XFOIL predictions because they provided test results for Re of $2.5 \times 10^{5}, 5.0 \times 10^{5}, 7.5 \times 10^{5}$, and $1.0 \times 10^{6}$, the lowest of which was representative of the average $\mathrm{Re}$ on the HAWT rotor at the maximum nominal wind speed [1]. Furthermore, this data set spanned $\alpha$ range of $-10^{\circ}$ to $110^{\circ}$ and included the effects of varying AR from infinity to 6 . However, only $C_{L}$ and $C_{D}$ data extending just beyond stall for a blade of infinite $A R$, the same extent to which the XFOIL code could be usefully employed, were gathered for comparison with the XFOIL predictions. The XFOIL analyses were performed for $\alpha$ ranging from $-14^{\circ}$ to $20^{\circ}$ at $\mathrm{Ma}=0.1$ and $\operatorname{Re}=2.5 \times 10^{5}, 5.0 \times 10^{5}$, and $7.5 \times 10^{5}$, respectively. $N_{\text {crit }}=7$ was prescribed for transition prediction. The prestall $C_{L}$ and prestall $C_{D}$ output from XFOIL in comparison to the experimental measurements are shown in Figure 4.

In reference to Figure 4 a few observations can be made about the accuracy of XFOIL with respect to the wind tunnel testing. First of all, XFOIL consistently overpredicted $C_{L}$ by an average of 0.2 units in $\alpha$ region where the lift curve slope was moderately constant and considerably underpredicted $C_{L}$ below $\alpha=-7^{\circ}$. Furthermore, as noted by [5], the experimental data saw the maximum lift coefficient, $C_{L_{m a x}}$, decrease with increasing Re, contrary to the trend for a typical $2 \mathrm{D}$ section [19] to which the XFOIL $C_{L}$ curves conformed. The experimental stall angle of attack, $\alpha_{\text {stall }}$, was near $18^{\circ}$ over the Re range of $2.5 \times 10^{5}$ to $7.5 \times 10^{5}$ whereas the XFOIL $\alpha_{\text {stall }}$ at $\operatorname{Re}=2.5 \times 10^{5}$ was at least $5^{\circ}$ lower than the higher $\operatorname{Re}$ counterparts. Since $\operatorname{Re}=2.5 \times 10^{5}$ represented a typical $\mathrm{Re}$ experienced by the HAWT rotor under test conditions, the use of XFOIL in calculating its power performance suggested possible errors in $\alpha_{\text {stall }}$ would be borne downstream in the extended BEM workflow. On the other hand, the Re effect on the lift characteristic, though noticeable only in and around stall, demonstrated the necessity of computing the prestall lift and prestall drag for blade elements based on local Re.

For drag, the Re effect was more difficult to discern. Although Ostowari and Naik [5] reported that they observed a rather pronounced effect of Re variation on the prestall drag by means of a wake rake survey, they did not provide additional data to elaborate this point. The XFOIL $C_{D}$ results shown in Figure 4 demonstrate that close to the stall point $C_{D}$ decreased with increasing Re. A more evident conclusion concerning drag was that fairly large discrepancies existed between experimental and numerical $C_{D}$ values which were a result of the method that drag was determined experimentally and with XFOIL. While Ostowari and Naik used the wind tunnel force balance system to obtain the drag measurement, $C_{D}$ output by XFOIL was the product of applying the Squire-Young formula at downstream infinity [13]. Over 

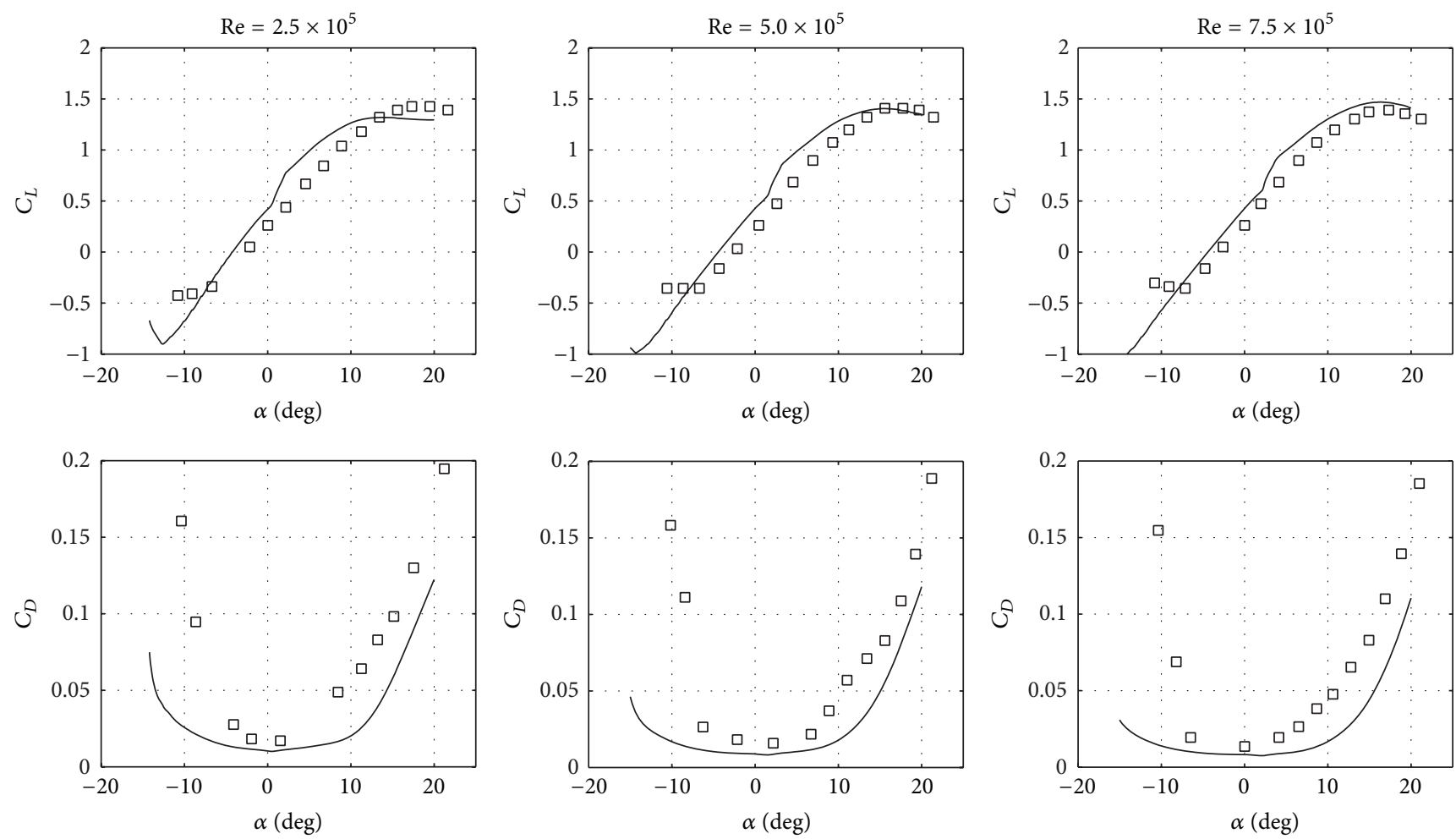

Figure 4: Coefficients of prestall lift and prestall drag as a function of angle of attack measured by Ostowari and Naik [5] (square marker) and predicted by XFOIL (solid line) for a NACA 4415 blade of infinite aspect ratio (AR) at Re $=2.5 \times 10^{5}, 5.0 \times 10^{5}$, and $7.5 \times 10^{5}$.

the range of $\alpha$ investigated XFOIL consistently output lower $C_{D}$ values.

3.2.2. Poststall Lift and Poststall Drag. The method first proposed by Viterna and Janetzke [15] for predicting poststall aerodynamic characteristics requires as input a reference $\alpha$, typically $\alpha_{\text {stall }}$, its corresponding $C_{L}$ and $C_{D}$, and the blade AR to extrapolate prestall $C_{L}$ and prestall $C_{D}$ to $\alpha=90^{\circ}$. The blade AR served the purpose of adjusting $2 \mathrm{D}$ airfoil data to model the aerodynamic behaviour of finite-length airfoils. For an $\mathrm{AR}$ of infinity, that is, $\mathrm{AR}=\infty$, the Viterna equations are as follows, assuming that $C_{D}$ of an infinite-length blade at $\alpha=90^{\circ}$ equals $C_{D}$ of an infinite-length flat plate normal to the freestream $\left(C_{D}=2\right)$ :

$$
\begin{aligned}
& C_{L}=\sin 2 \alpha+\left(C_{L_{\text {stall }}}-\sin 2 \alpha_{\text {stall }}\right) \frac{\sin \alpha_{\text {stall }}}{\cos ^{2} \alpha_{\text {stall }}} \frac{\cos ^{2} \alpha}{\sin \alpha} \\
& C_{D}=2 \sin ^{2} \alpha+\left(C_{D_{\text {stall }}}-2 \sin ^{2} \alpha_{\text {stall }}\right) \frac{\cos \alpha}{\cos \alpha_{\text {stall }}} .
\end{aligned}
$$

Tangler and Kocurek [17] provided additional guidelines for the Viterna method as a global poststall model and noted that the accuracy of the Viterna equations depended on the magnitude of $C_{L}$ and $C_{D}$ associated with the reference $\alpha$ and on whether $C_{L} / C_{D}$ at the reference $\alpha$ agreed with flat plate theory. They also used a weighted AR that resulted from the blade radius divided by the local chord at $80 \%$ radius, which was adopted in the current study.
TABLE 4: AERODAS input parameters that need to be adjusted for finite aspect ratio. The prime notation means that the parameters are for an infinite aspect ratio airfoil; without it, they would be for a finite aspect ratio airfoil.

\begin{tabular}{ll}
\hline$A C L 1^{\prime}$ & Angle of attack at maximum prestall $C_{L}$ \\
$A C D 1^{\prime}$ & Angle of attack at maximum prestall $C_{D}$ \\
$C L 1^{\prime}$ & Maximum prestall $C_{L}$ \\
$C D 1^{\prime}$ & Maximum prestall $C_{D}$ \\
$S 1^{\prime}$ & Slope of linear segment of prestall lift curve \\
\hline
\end{tabular}

The AERODAS model [16] was developed empirically by determining the best fit to a large database of airfoils with various combinations of $\mathrm{AR}, \mathrm{Re}, \alpha$, and so forth. Aside from the input parameters for the Viterna model it requires as input the zero-lift $\alpha$, its corresponding $C_{D}$, the slope of the linear segment for the prestall $C_{L}$ curve, and the maximum prestall $C_{D}$. The AERODAS model allows for correcting the infinite-length airfoil data for AR by adjusting 5 of the 7 input parameters. See Table 4 for the list of these AERODAS input parameters. In the case of $\mathrm{AR}=\infty$, however, the input parameters need not be adjusted; that is, $A C L 1=A C L 1^{\prime}, A C D 1=A C D 1^{\prime}, C L 1 \max =C L 1 \max ^{\prime}$, $C D 1 \max =C D 1 \max ^{\prime}$, and $S 1=S 1^{\prime}$. Furthermore, the two empirical functions of AR involved in calculating the maximum poststall $C_{L}$ and poststall $C_{D}$, respectively, are reduced to $F 2=1$ and $G 2=1$. 

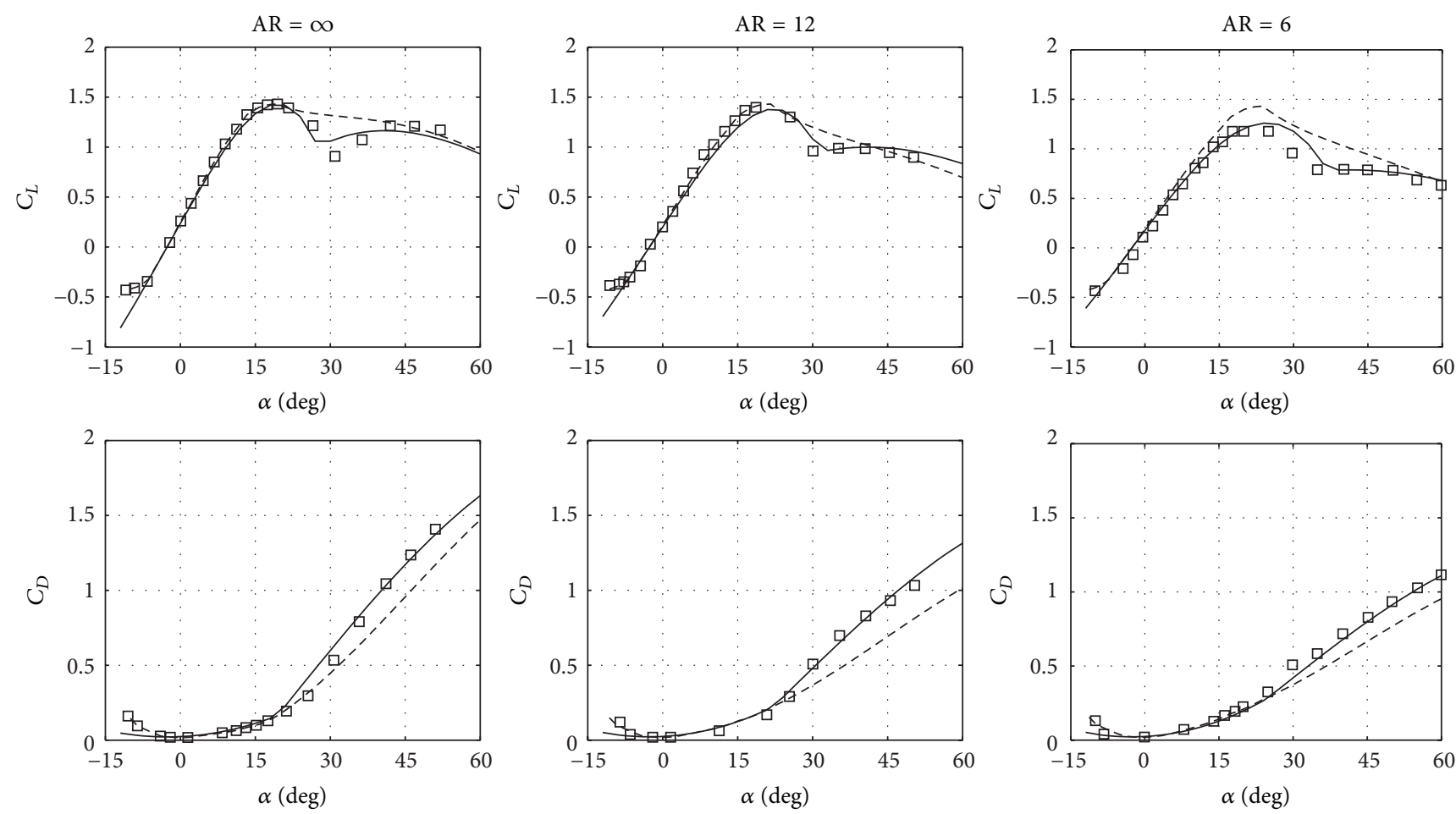

Figure 5: Coefficients of poststall lift and poststall drag as a function of angle of attack measured by Ostowari and Naik [5] (square marker) and predicted by AERODAS (solid line) and Viterna (dashed line) for NACA 4415 blades having aspect ratios (AR) of infinity, 12, and 6 at $\operatorname{Re}=2.5 \times 10^{5}$.

Since the NACA 4415 data set [5] extended to $\alpha=110^{\circ}$, it was also used to assess how well the two poststall models, Viterna and AERODAS, were able to predict $C_{L}$ and $C_{D}$ beyond stall. The prestall $C_{L}$ and $C_{D}$ curves of the blade with infinite $\mathrm{AR}$ at $\mathrm{Re}=2.5 \times 10^{5}$ from the experimental data set in question were input to the Viterna and AERODAS models, which were implemented for $\alpha$ ranging from stall to $60^{\circ}$ and for $\mathrm{AR}=\infty, 12$, and 6 , respectively. The output by the Viterna and AERODAS models, which included the poststall $C_{L}$ and $C_{D}$ data as well as the prestall $C_{L}$ and $C_{D}$ data adjusted as per $A R$ versus the experimental measurements at $\mathrm{Re}=2.5 \times 10^{5}$, is presented in Figure 5.

As shown in Figure 5, the AERODAS model produced $C_{L}$ and $C_{D}$ that, in general, followed the experimental data points more closely in the poststall regime than did the Viterna output over the entire range of AR investigated. The latter consistently underpredicted $C_{D}$ in the poststall regime. Moreover, the AERODAS model was able to predict the occurrence of secondary stall whereas the Viterna output failed to show any sign of the phenomenon. The robust performance of the AERODAS method was expected since one of the data sets used in AERODAS modeling [16] was that by Ostowari and Naik [5]. However, one subtle advantage the Viterna model had over the AERODAS model, as reflected in view of $A R=6$ and 12, was that the former predicted the location of $C_{L_{\max }}$ more accurately than the latter, which tended to delay the occurrence of $C_{L_{\max }}$ to a higher $\alpha$.

\section{Results and Discussion}

4.1. General Discussion. The primary BEM output of interest was coefficient of power as a function of tip speed ratio $(\lambda)$. Before presenting $C_{p}$ versus $\lambda$ resulting from different input parameters, it is necessary to discuss the number of iterations and the number of blade elements, $n$, used by the extended BEM algorithm to compute meaningful power coefficients. For every parametric combination investigated the number of iterations to achieve convergence varied loosely with $\lambda$. For larger tip speed ratios a second iteration, in general, brought $C_{p}$ within $0.1 \%$ of $C_{p}$ output of the subsequent iteration. However, for smaller tip speed ratios, where the blade airfoil sections were stalled and the interpolation of aerodynamic properties was based on the poststall lift and drag data, $C_{p}$ output displayed oscillatory behaviour due in part to the comparatively small numerical values and in part to the sensitivity of the poststall drag models to slight changes in their input parameters such as $\alpha_{\text {stall }}$. Therefore, a maximum percentage uncertainty of $5 \%$ was present in $C_{p}$ values computed for small tip speed ratios. As for an optimal number of blade elements, it was determined by comparing $C_{p}$ based on an increasing number of blade elements. The power curves with $n=6,10$, and 14 elements are plotted in Figure 6. Six blade elements led to overpredictions of $C_{p}$ at larger tip speed ratios whereas the results based on 10 and 14 blade elements nearly overlapped each other over the entire range of $\lambda$, indicating convergence of results. Hence, the aerodynamic span of 
TABLE 5: Maximum and minimum Re seen by the aerodynamic span of the blade at $\lambda=4$ and $\lambda=10$ with $U_{\infty}=7.3 \mathrm{~m} / \mathrm{s}$ and $U_{\infty}=$ $11.1 \mathrm{~m} / \mathrm{s}$. Model input: $N_{\text {crit }}=7$, AERODAS, tip loss model on.

\begin{tabular}{lccc}
\hline$U_{\infty}(\mathrm{m} / \mathrm{s})$ & $\lambda$ & Minimum $\operatorname{Re}\left(\times 10^{5}\right)$ & Maximum $\operatorname{Re}\left(\times 10^{5}\right)$ \\
\hline \multirow{2}{*}{7.3} & 4 & 1.04 & 1.49 \\
& 10 & 2.44 & 3.50 \\
\hline \multirow{2}{*}{11.1} & 4 & 1.59 & 2.27 \\
& 10 & 3.71 & 5.32 \\
\hline
\end{tabular}

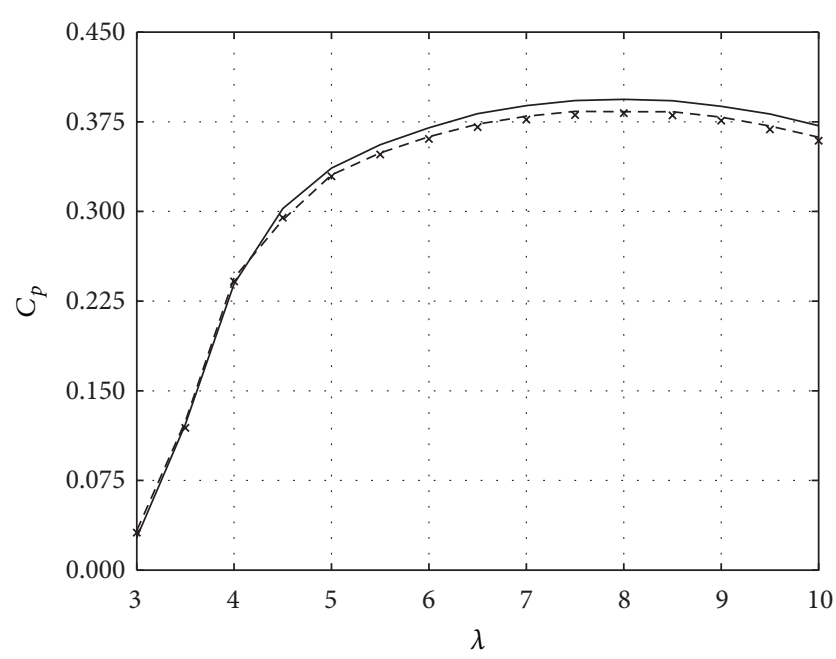

Figure 6: $C_{p}$ versus $\lambda$ for $n=6$ (solid line), 10 (dashed line), and 14 (cross marker) blade elements. Model input: $U_{\infty}=11 \mathrm{~m} / \mathrm{s}, N_{\text {crit }}=7$, AERODAS, tip loss model on.

the blade was divided into 10 elements for subsequent calculations, that is, $21.5 \mathrm{~cm}$ wide per element. The discrepancy between the power curves based on coarser and finer blade element distributions validated the necessity of using the aerodynamic properties of local blade sections. Meanwhile, it suggested possible errors in modeling the power performance of the HAWT used for the current study, which stemmed from linear interpolation of the blade section profiles from the smoothed measured airfoil profiles at the root, midsection, and tip of the aerodynamic span.

4.2. Effect of Reynolds Number. It was evident from the power curves obtained with a nominal wind speed of $7.3 \mathrm{~m} / \mathrm{s}$ and $11.1 \mathrm{~m} / \mathrm{s}$ (Figure 7) that $C_{p}$ was not only a function of $\lambda$ but also strongly dependent on Re. Table 5 illustrates how Reynolds numbers based on converged iterations of the extended BEM algorithm varied with $U_{\infty}$. Regardless of the poststall model choice or how the finite AR effect was captured, as reflected in turning on or off the tip loss model, $U_{\infty}=11.1 \mathrm{~m} / \mathrm{s}$ resulted in larger $C_{p}$ for $3 \leq \lambda \leq 5$ than $\operatorname{did} U_{\infty}=7.3 \mathrm{~m} / \mathrm{s}$. The discrepancy was even more discernible in the case of AERODAS, amounting to over $50 \%$ at $\lambda=4$. The contributing factor to the trend could be traced back to the effect of Re on the prestall lift and drag coefficients; namely, $C_{L_{\max }}$ of every airfoil section increased with $\operatorname{Re}$ (see Section 3.2.1), leading to higher lift in the poststall region through the poststall models. Since power production was proportional to lift, larger $C_{p}$ resulted. Changes in the freestream velocity indeed impact the coefficient of power at a given tip speed ratio; a similar trend could be said of the raw experimental $C_{p}$ by observing closely the scatter of data points for $3 \leq \lambda \leq 5$ in Figure 8 (owing to the limitation of the test rig, the maximum $\lambda$ for which experimental $C_{p}$ could be obtained dropped with increasing $U_{\infty}$ such that $\lambda$ ranged from 0.8 to 4.5 for $U_{\infty}=$ $11.1 \mathrm{~m} / \mathrm{s}[1])$.

4.3. Effect of Transition Amplification Factor. Although the parametric study was carried out with $N_{\text {crit }}$ set to $6,7,8$, 9 , and 10 , only $C_{p}$ curves obtained with $N_{\text {crit }}=6,8$, and 10 were included in Figure 9 to show with clarity the effect of transition amplification factor on prediction of power production. From $N_{\text {crit }}=6$ to $N_{\text {crit }}=10$ an increase in $C_{p}$ by less than $2 \%$ on average was present between $\lambda=5$ and $\lambda=9$. Consequently, from the perspective of modeling, $N_{\text {crit }}$ could be any number between 7 and 10. By investigating the aerodynamic data corresponding to the respective transition amplification factors, the reason for the increase in $C_{p}$ was illuminated. While $N_{\text {crit }}=6$ and $N_{\text {crit }}=10$ resulted in virtually the same prestall drag curve, the latter yielded higher lift toward stall, thereby giving rise to increased lift immediately before and after the stall point, which in view of power production translated into the region of $C_{p}$ curve preceding and following the peak $C_{p}$ value. According to the review by van Ingen [20], which associated $N_{\text {crit }}$ ranging from 9.4 to 9.9 with a overall RMS turbulence level of $12 \%$ to $20 \%$ of the free stream speed, $N_{\text {crit }}=10$ could well represent the flow scenario simulated in the current study since the turbulence intensity in testing was found to vary from $10.2 \%$ to $14.9 \%$ depending on the freestream velocity [1]. However, as noted by various researchers $[20,21]$, the freestream turbulence level is not the only factor influencing transition. Therefore, the choice of a representative $N_{\text {crit }}$ was convenient for modeling but did not necessarily encompass all the physics of transition encountered by the turbine blades.

4.4. Comparison of Experimental and Extended $B E M C_{p}$. The impact on $C_{p}$ of the remaining two input parameters of the parametric study, namely, the poststall model and how the effect of finite AR of the blade was captured, is presented in conjunction with the experimental power curve in Figures 10 and 11. Note that the experimental power curve resulted from curve fitting to scattered raw experimental $C_{p}$ data (Figure 8) and was found to contain a percentage uncertainty of approximately 7\% [1]. Because $C_{p}$ data obtained experimentally for $U_{\infty}=11.1 \mathrm{~m} / \mathrm{s}$ only extended to $\lambda=4.5$, the curve fit was a closer representation of $C_{p}$ data obtained experimentally for $U_{\infty}=7.3 \mathrm{~m} / \mathrm{s}$. Therefore, the ensuing discussion on comparison of experimental and extended BEM $C_{p}$ will be in reference to Figure 10.

The tip speed ratio representing the peak of a $C_{p}$ curve is herein referred to as $\lambda_{\text {peak }}$. AERODAS and Viterna predicted $\lambda_{\text {peak }}=8$ and $\lambda_{\text {peak }}=8.5$, respectively, as a result of the former tending to delay the occurrence of $C_{L_{\max }}$ to a higher $\alpha$ (see Section 3.2.2). $\lambda_{\text {peak }}$ for the experimental $C_{p}$ curve appeared to be 8 although the same point marked the last data point. Since the experimental $C_{p}$ data did not reach a peak 


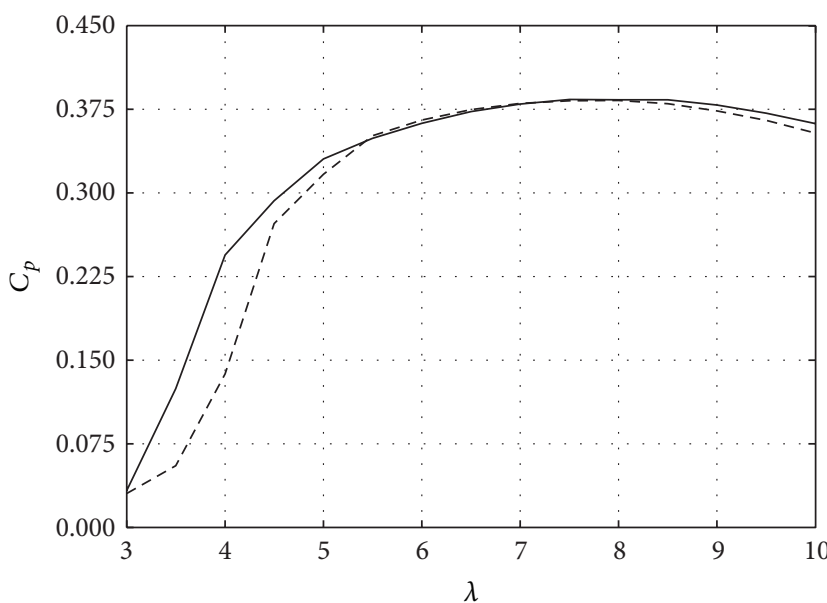

(a)

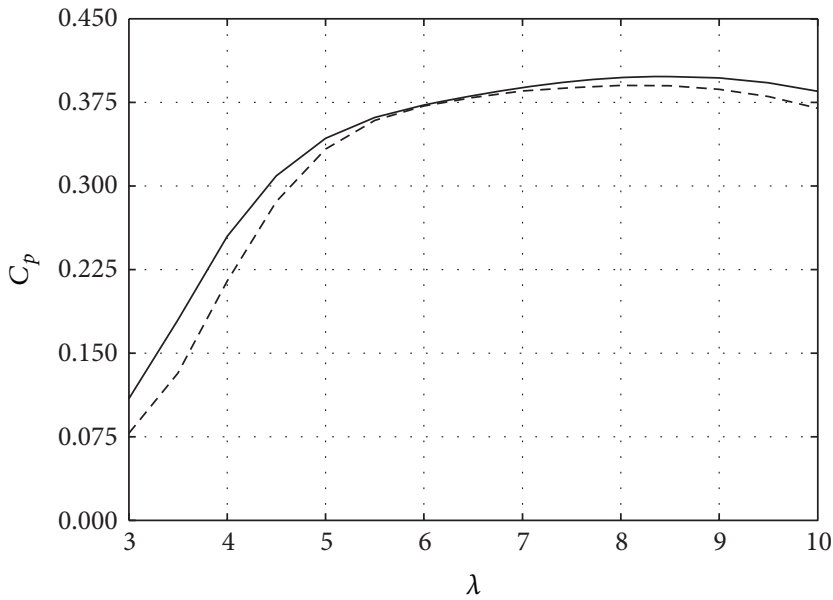

(c)

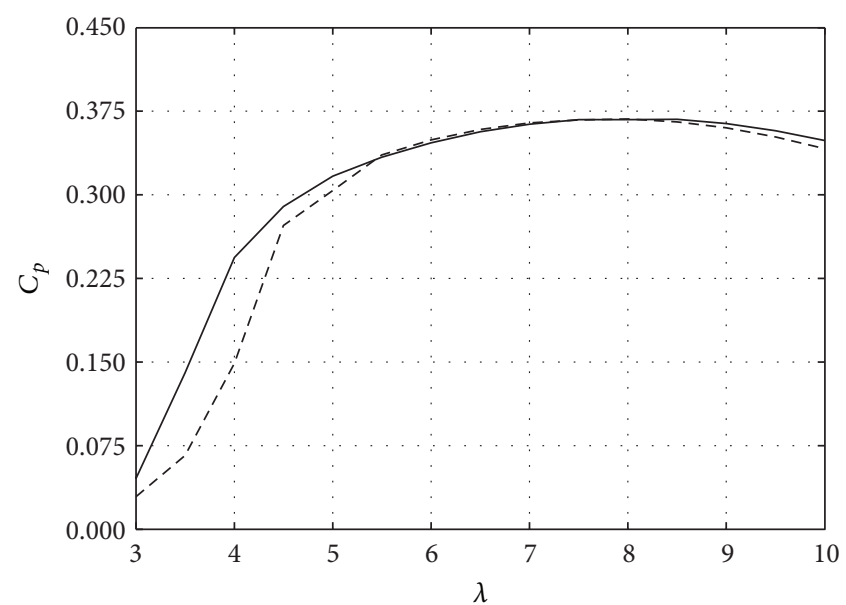

(b)

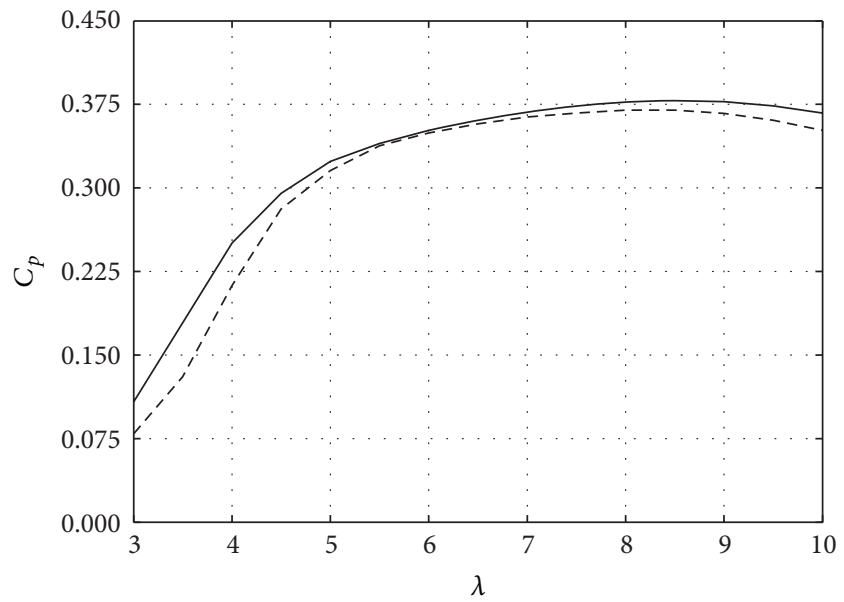

(d)

FIgURE 7: $C_{p}$ versus $\lambda$ for $U_{\infty}=11.1 \mathrm{~m} / \mathrm{s}$ (solid line) and $U_{\infty}=7.3 \mathrm{~m} / \mathrm{s}$ (dashed line). Model input: (a) $N_{\text {crit }}=7$, AERODAS, tip loss model on; (b) $N_{\text {crit }}=7$, AERODAS, tip loss model off; (c) $N_{\text {crit }}=7$, Viterna, tip loss model on; (d) $N_{\text {crit }}=7$, Viterna, tip loss model off.

and subsequently decrease, the actual $\lambda_{\text {peak }}$ was potentially greater than 8 , in light of which Viterna was therefore the more favorable model. Moreover, with every other input parameter held invariant, AERODAS consistently yielded smaller power coefficients than did Viterna, irrespective of whether or not the tip loss model was turned on. The discrepancies only increased toward the lower and upper limits of $\lambda$ range investigated. At lower tip speed ratios, Viterna performed better in matching the experimental $C_{p}$ curve. The reason why $C_{p}$ curves computed using Viterna and AERODAS still differed for $\lambda \geq \lambda_{\text {peak }}$, when neither model was used to correct for finite AR, that is, when the aerodynamic loads on the blade depended on the prestall lift and prestall drag, was that AERODAS interpreted prestall $C_{L}$ as having a constant slope region [16] though that was not always a characteristic of the XFOIL $C_{L}$ curves for the Re range investigated.

As for the effect of turning on and off the tip loss model, the impact is made clear by both Figures 10 and 11. Regardless of the choice of the poststall model, correcting for the effect of finite AR through either AERODAS or Viterna and in turn disabling the tip loss model saw $C_{p}$ drop markedly for $\lambda \geq 5$ in reference to $C_{p}$ obtained with the tip loss model enabled. The decrease in $C_{p}$ made physical sense. Modeling the aerodynamic properties of every turbine blade section on the lift and drag of a finite-length airfoil implied that nowhere along the blade did 2D flow dominate, which was uncharacteristic of the blade particularly before stall and consequently led to more significant deviation from the experimental $C_{p}$ curve in the corresponding $\lambda$ range. On the other hand, for $\lambda \leq 5.5$ it was observed from the Viterna curves in Figure 10 that adjusting the $2 \mathrm{D}$ airfoil data for finite AR brought the modeled $C_{p}$ results closer to their experimental counterparts, suggesting the need for capturing in some degree the cross-element flow interactions despite the inherent assumptions of classical BEM theory. Hence, a reasonable rule of thumb was to turn on the tip loss model prior to stalling of a good portion of the aerodynamic span of the blade and turn off the tip loss model after it.

To summarize the foregoing observations, the experimental power curve was best predicted by the extended BEM simulation that used the Viterna method for producing the 


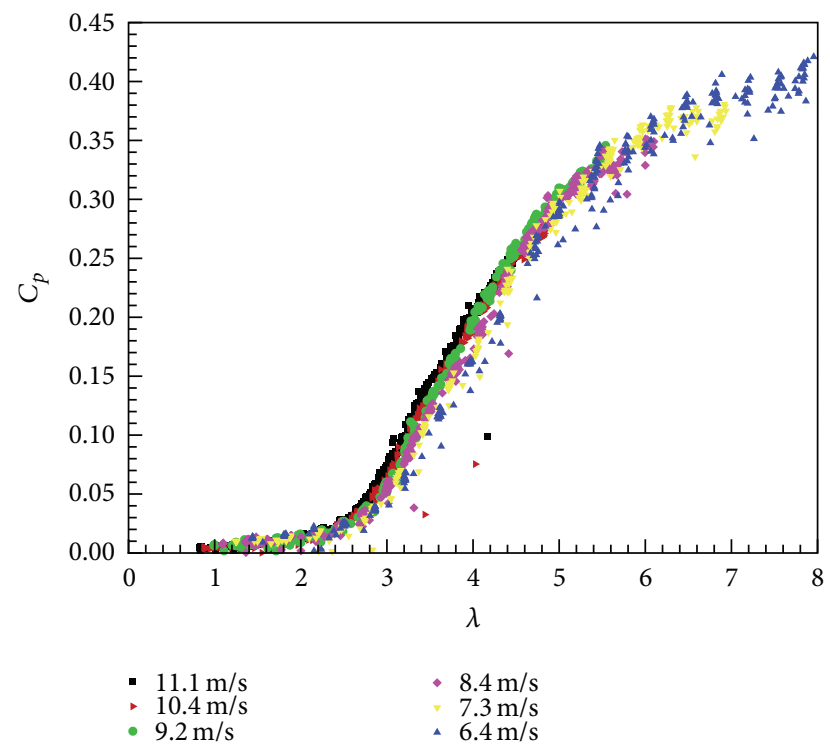

Figure 8: Raw experimental $C_{p}$ versus $\lambda$ results for a $U_{\infty}$ range of $6.4 \mathrm{~m} / \mathrm{s}$ to $11.1 \mathrm{~m} / \mathrm{s}$ [1].

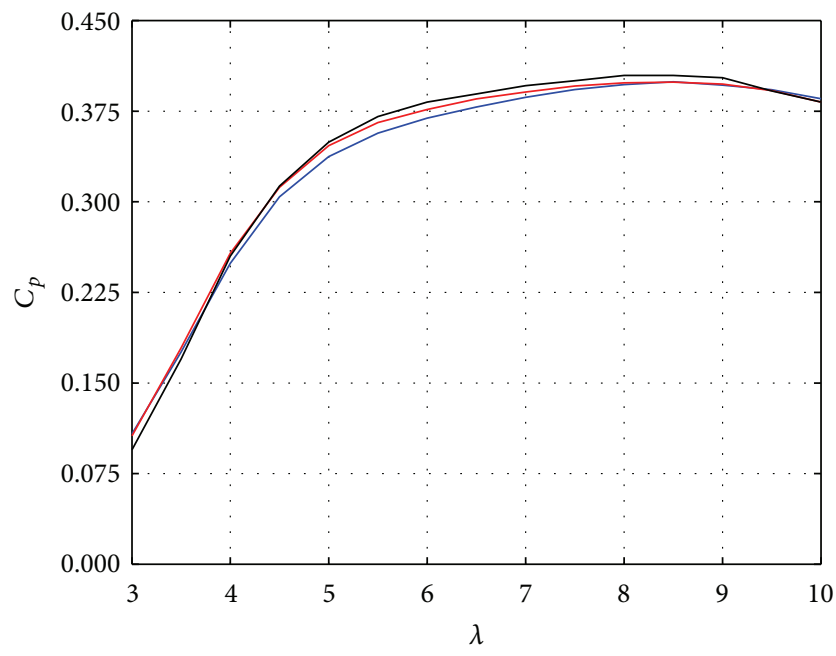

Figure 9: $C_{p}$ versus $\lambda$ for $N_{\text {crit }}=6$ (blue), 8 (red), and 10 (black). Model input: $U_{\infty}=11.1 \mathrm{~m} / \mathrm{s}$, Viterna, tip loss model on.

poststall aerodynamic data, corrected for the finite AR effect with the poststall model after stall and with the tip loss model before it. $C_{p}$ peak was accurately modeled. The largest difference between the experimental and extended BEM $C_{p}$ curves which was $6.6 \%$ occurred at $\lambda=8$ and was within the percentage uncertainty of the experimental data.

\section{Conclusions}

By incorporating the computation of aerodynamic properties into its iterative procedure, the extended BEM algorithm ensured that the chord Reynolds number seen by a blade element was based on the converged axial and tangential induction factors and that the power production by the blade element agreed with its lift and drag data at the same Reynolds

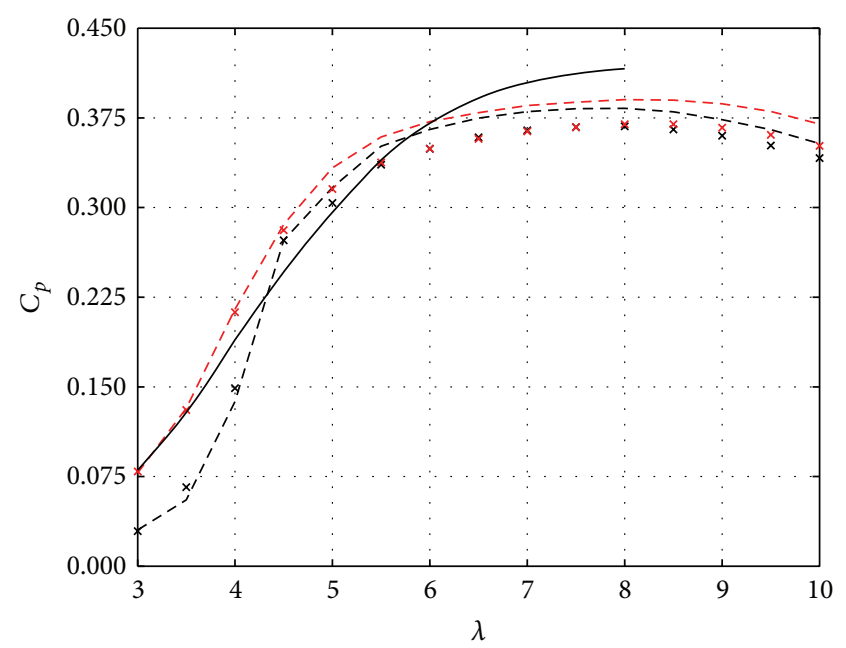

FIGURE 10: $C_{p}$ versus $\lambda$ obtained experimentally (solid line) and with the extended BEM algorithm for $U_{\infty}=7.3 \mathrm{~m} / \mathrm{s}$. Model input: $N_{\text {crit }}=$ 7, AERODAS (black) or Viterna (red), tip loss model on (dashed line) or off (cross marker).

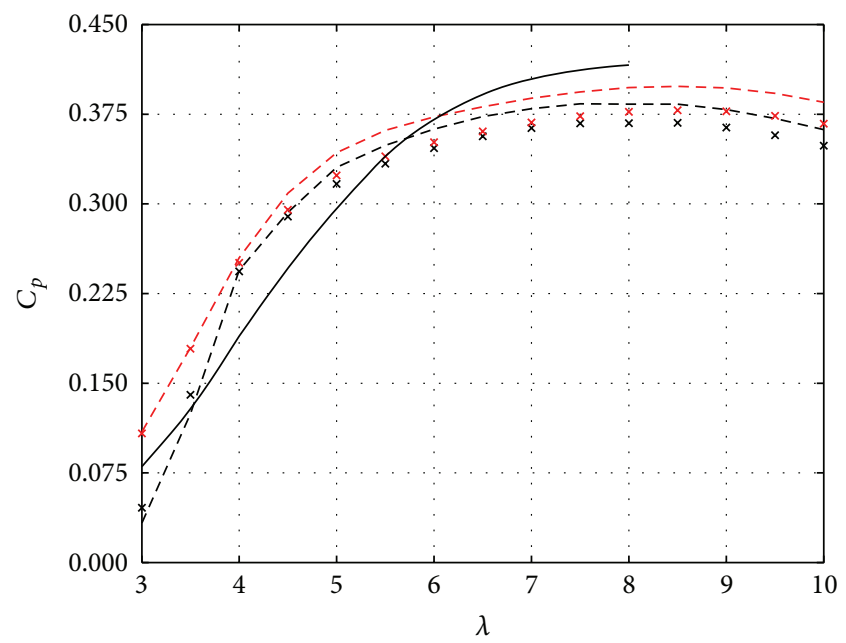

FIGURE 11: $C_{p}$ versus $\lambda$ obtained experimentally (solid line) and with the extended BEM algorithm for $U_{\infty}=11.1 \mathrm{~m} / \mathrm{s}$. Model input: $N_{\text {crit }}=7$, AERODAS (black) or Viterna (red), tip loss model on (dashed line) or off (cross marker).

number. Convergence or slight oscillation of $C_{p}$ was generally obtained after a few iterations. The experimental power curve for the HAWT of the current study was closely matched by the extended BEM simulation.

The parametric study using the extended BEM algorithm revealed in essence the close association of the power curve behaviour with the aerodynamic characteristics of the blade elements. For a turbine blade with variable cross sections, it was important to discretize the aerodynamic span into an adequate number of blade elements. A guideline based on the HAWT of the current study was that each blade element should be at least $0.2 \mathrm{~m}$ wide for a $4.3 \mathrm{~m}$ diameter rotor. The dependence of turbine power output on Reynolds number in the range of $1.0 \times 10^{4}$ to $1.0 \times 10^{6}$ was strong particularly when 
the blades were stalled, supported by both experimental and modeling results. Transition prediction also affected overall power performance, albeit to a lesser degree. $C_{p}$ gradually increased with larger transition amplification factors in the region of the peak $C_{p}$ value. Finally, in order to more accurately capture the finite AR effect of the blade, the tip loss model should be selectively turned on or off, the former being preferable when the blades were not stalled or close to stall.

\section{Competing Interests}

The authors declare that they have no competing interests.

\section{Acknowledgments}

The authors would like to acknowledge the support of the Natural Sciences and Engineering Research Council of Canada and the Ontario Centres of Excellence.

\section{References}

[1] B. Gaunt and D. A. Johnson, "Wind turbine performance in controlled conditions: experimental results," International Journal of Green Energy, 2012.

[2] D. Johnson, A. Abdelrahman, and D. Gertz, "Experimental indirect determination of wind turbine performance and Blade Element Theory parameters in controlled conditions," Wind Engineering, vol. 36, no. 6, pp. 717-738, 2012.

[3] M. M. Hand, D. A. Simms, L. J. Fingersh et al., "Unsteady aerodynamics experiment phase VI: wind tunnel test configurations and available data campaigns," Tech. Rep. NREL/TP-500-29955, NREL, 2001.

[4] J. G. Schepers and H. Snel, "Model experiments in controlled conditions: final report," Tech. Rep. ECN-E-07-042, ECN, 2007.

[5] C. Ostowari and D. Naik, "Post stall studies of untwisted varying aspect ratio blades with an NACA 4415 airfoil section-part I," Wind Engineering, vol. 8, no. 3, pp. 176-194, 1984.

[6] B. Gaunt, Power generation and blade flow measurements of a full scale wind turbine [M.S. thesis], University of Waterloo, Waterloo, Canada, 2009.

[7] H. L. Morgan, "AFSMO/AFSCL-airfoil smoothing and scaling," NASA LAR-13132, NASA, Washington, Wash, USA, 1994.

[8] I. H. Abbot and A. E. von Doenhoff, Theory of Wing Sections, Dover, New York, NY, USA, 1959.

[9] T. Burton, D. Sharpe, N. Jenkins, and E. Bossanyi, Wind Energy Handbook, John Wiley \& Sons, 2006.

[10] M. Hansen, Aerodynamics of Wind Turbines, Earthscan, Sterling, Va, USA, 2008.

[11] J. Manwell, J. McGowan, and A. Rogers, Wind Energy Explained, John Wiley \& Sons, 2009.

[12] P. B. S. Lissaman, "Low-Reynolds-number airfoils," Annual Review of Fluid Mechanics, vol. 15, pp. 223-239, 1983.

[13] M. Drela and H. Youngren, "XFOIL: an analysis and design system for low Reynolds number airfoils," in Low Reynolds Number Aerodynamics: Proceedings of the Conference Notre Dame, Indiana, USA, 5-7 June 1989, vol. 54 of Lecture Notes in Engineering, pp. 1-12, Springer, Berlin, Germany, 1989.

[14] M. S. Selig, A. Gopalarathnam, P. Giguere, and C. A. Lyon, "Systematic airfoil design studies at low Reynolds numbers," in Fixed Flapping and Rotary Wind Vehicles at Very Low Reynolds
Numbers, pp. 143-167, American Institute of Aeronautics and Astronautics, 2001.

[15] L. Viterna and D. Janetzke, "Theoretical and experimental power from large horizontal axis wind turbines," Tech. Rep. NASA TM-82944, NASA, 1982.

[16] D. A. Spera, "Models of lift and drag coefficients of stalled and unstalled airfoils in wind turbines and wind tunnels," Tech. Rep. NASA/CR-2008-215434, NASA, Cleveland, Ohio, USA, 2008.

[17] J. Tangler and J. D. Kocurek, "Wind turbine post-stall airfoil performance characteristics guidelines for blade-element momentum methods," Tech. Rep. NREL/EL-500-36900, National Renewable Energy Laboratory,, Golden, Colo, USA, 2004.

[18] M. J. Hoffmann, R. Ramsay, and G. Gregorek, "Effects of grit roughness and pitch oscillations on the NACA 4415 airfoil," NREL/TP 442-7815, 1996.

[19] J. Anderson, Aircraft Performance and Design, McGraw-Hill Inc, 1999.

[20] J. L. van Ingen, "The e-to-the-N method for transition prediction. Historical review of work at TU delft," in Proceedings of the 38th Fluid Dynamics Conference and Exhibit, American Institute of Aeronautics and Astronautics, Seattle, Wash, USA, 2008.

[21] T. Cebeci, Stability and Transition: Theory and Application, Horizons, 2004 


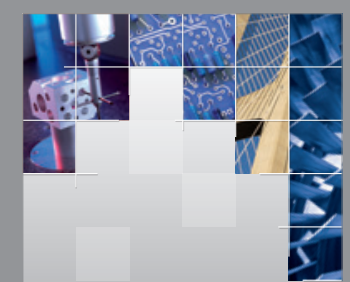

\section{Enfincering}
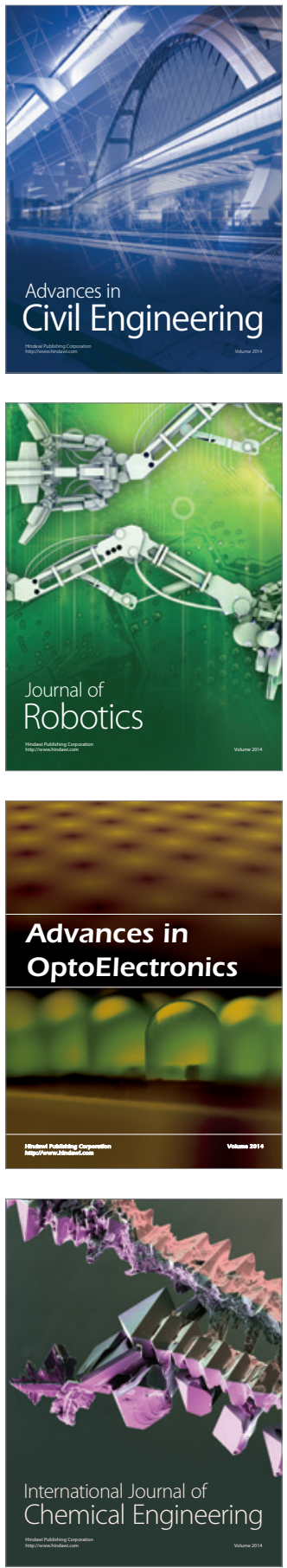

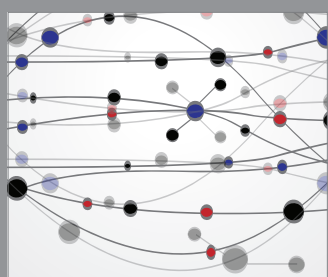

The Scientific World Journal

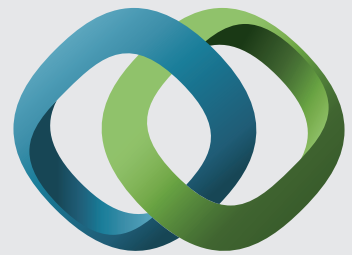

\section{Hindawi}

Submit your manuscripts at

http://www.hindawi.com
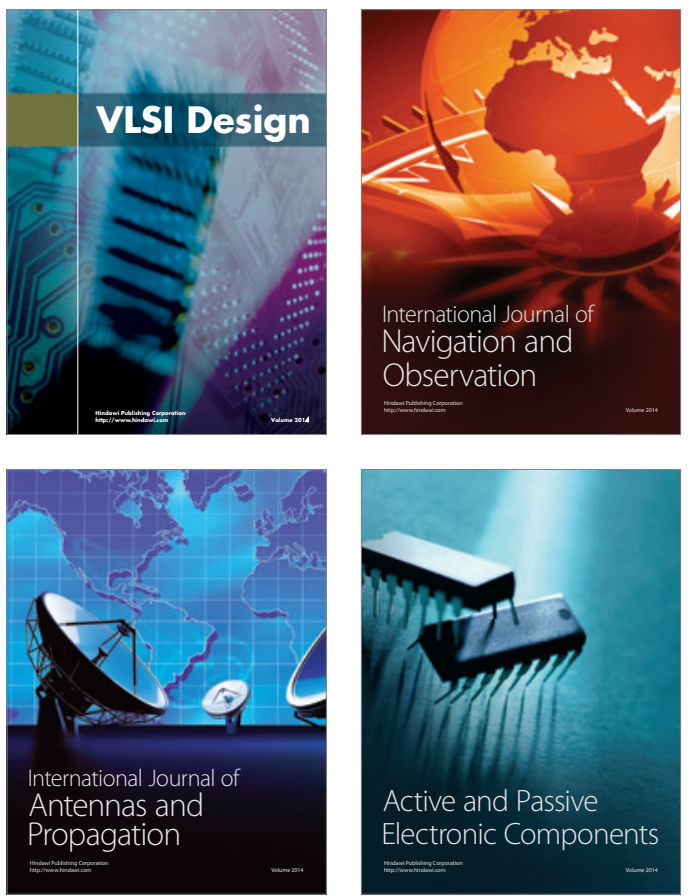
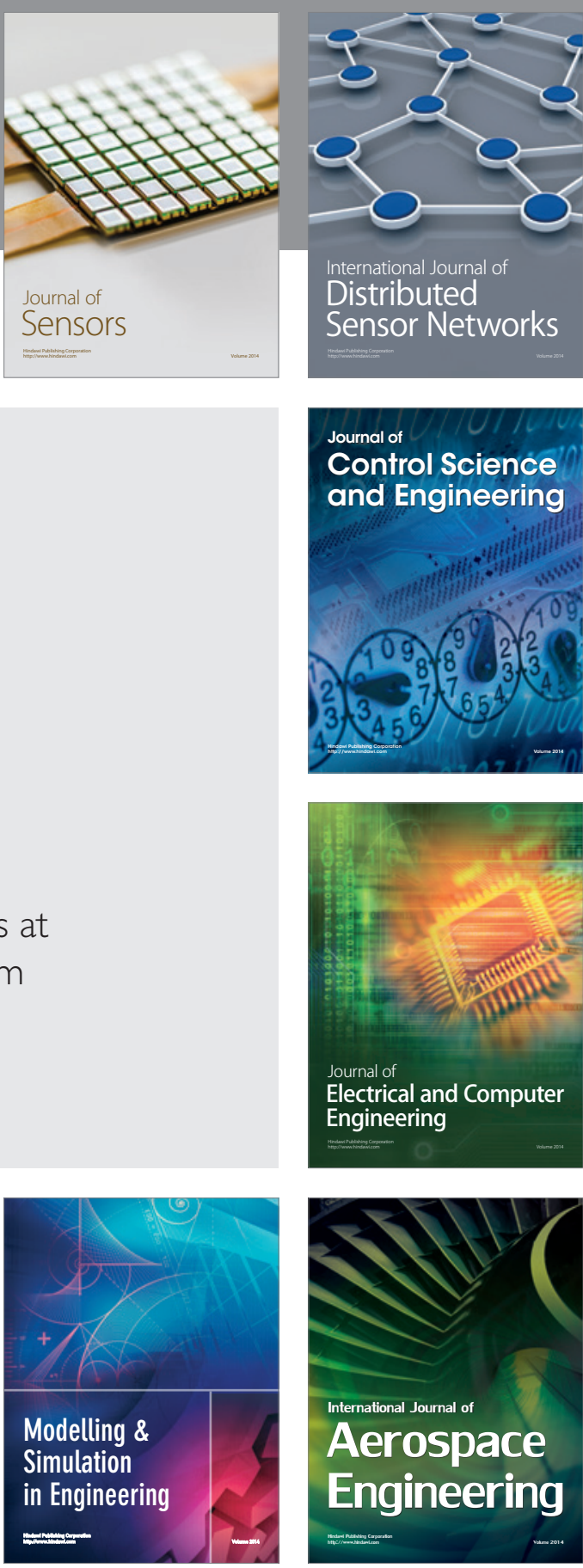

International Journal of

Distributed

Sensor Networks

Journal of

Control Science

and Engineering
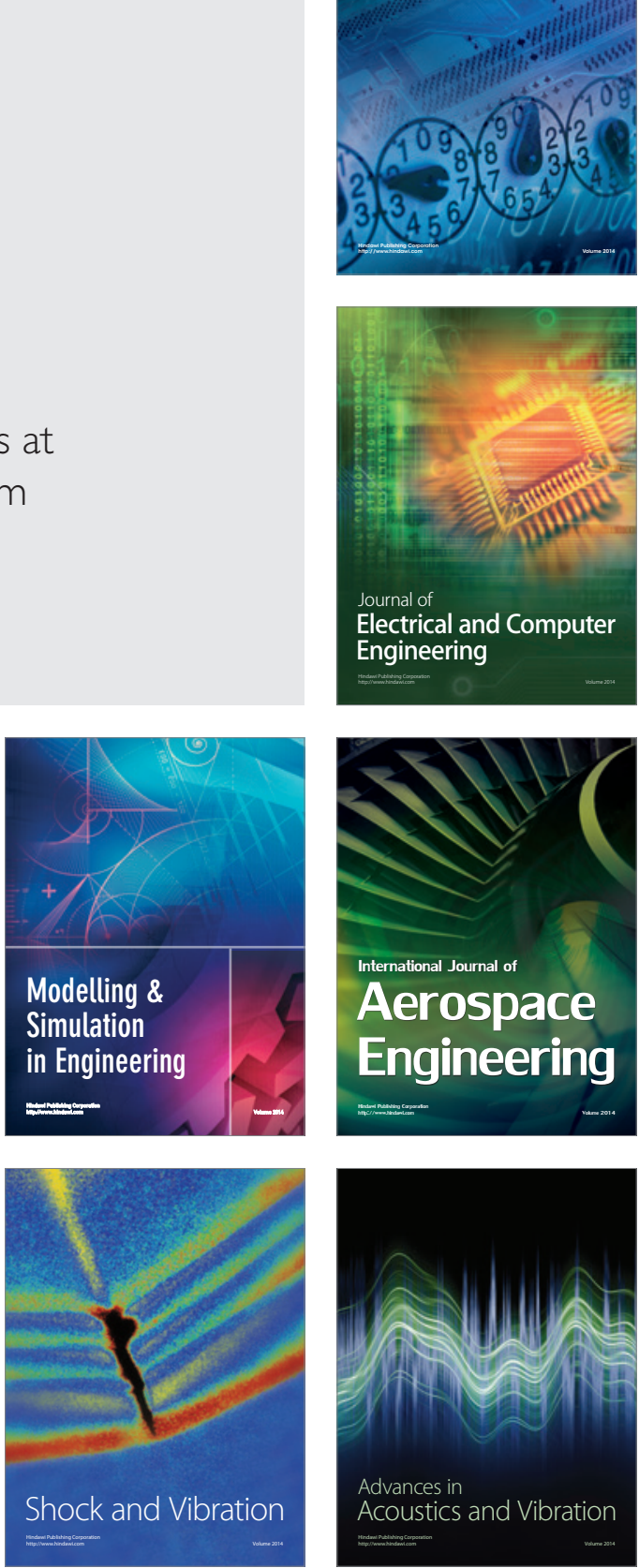